\title{
The Effects of Robots on the Long-Run Economic Growth
}

\author{
Jun LIU, Long REN, Xiang CHU*, Daqing GONG
}

\begin{abstract}
With the rapid development of artificial intelligence (Al) technology, the application of robots is widening and deepening. Due to the fact that robots are capable of machine learning and deep learning, we establish a theoretical model of the production process by considering the difference in learning ability between robots and labor forces, namely the difference in "learning by doing" ability. Based on this, the influence of robots on long-term economic growth is investigated. Our analytical results show that when the learning ability of robots is stronger than human capital, there will be no balanced growth path for the economy, and the economy will eventually show a sustained growth pattern, and the growth rate of capital per capita, output per capita and robot per capita will keep growing. However, more robots are not always better. There is an optimal robot investment ratio to maximize the long-term growth rate of output per capita. Managers should not only increase investments in robots. How to improve the learning ability of robots is also of great importance.
\end{abstract}

Keywords: Al technology; economic growth; learning ability; production; robots

\section{INTRODUCTION}

In recent years, with the rapid development of artificial intelligence (AI) technology, a new round of scientific and technological revolution and industrial transformation is gradually taking shape. This cutting-edge technology is integrated with other ones, e.g., big data, machine learning, and robot technology, and reshaped the economic activities to a larger extent than ever before. Numerous industrial practices have witnessed the penetration of $\mathrm{AI}$ and robot technologies into our daily life, reshaping the landscape of business eco-systems. For instance, on October 27, 2017, according to a report by CNBC [33], the retail giant Wal-Mart has deployed shelf-scanning robots in 50 locations in the United States, which are mainly used to check inventory, prices, and misplaced items.

The worldwide robot market is developing and expanding rapidly, and countries around the world are utilizing more and more robots. According to a report from the international federation of robotics (IFR), the volumes of robots are growing at a rate of about 6 percent per year globally. According to IFR's 2016 robot report, the global demand for robots is projected to grow at a rate of 12 percent per year between 2016 and 2019. With the increasing employments of robots and the continuous development of the world robot market, this new innovation will inevitably have a profound impact on economic growth.

There are some advantages and disadvantages of the robot investment. There are ample real-life examples and literature emphasizing the positive effects of robots on short-term economic growth. Existing empirical studies support the point that the use of industrial robots can increase labor productivity [1-6]. Prettner [7] believes that the use of robots can indeed promote the economy, and even in some cases, the economy can achieve permanent growth even without technological progress.

However, there is still no consensus on whether the application of robots will boost economic growth in the long run. Some literature suggests that the substitution effects of robots will inhibit the growth of employment and wages, thus prohibiting the increase of investment, leading to the reduction of the welfare of young workers and their children and grandchildren [8-10].
Perhaps one day in the future, as AI technology and machine learning capabilities continue to improve, as long as the intelligence of robots can surpass the general intelligence of human beings, robots will not simply exist as a replacement of labor, which will completely change the economic development landscape of our society. Nowadays, we still lack systematic thinking and rational expectations of this emerging thing.

Motivated by the aforementioned industrial practice and existing works, we are trying to address the following research questions:

(1) What are the impacts of robots on the output and the return gap under the perfect competition conditions?

(2) What are the impacts of robots on the long-term economic growth rate? Will the use of robots lead the economy to sustained growth?

(3) What factors will influence the long-term economic growth rate? Is there an optimal robot investment ratio to maximize the long-term growth rate of output per capita?

To address these research questions aforementioned, we establish a theoretical model of long-term economic growth incorporating the learning ability of robots different from labor force. We then explore the influence of robots on long-term economic growth.

We make contributions to the existing literature in several-folds. First, although several prior pieces of research [10-12] discuss the impacts of the robot for the labor market and economic development, most of them simply regard the robots as a substitute during the production process. Most of these studies have not considered the characteristics of robots in their model. In this paper, we take into account the difference in learning ability between robots and labor forces in the production process, namely the difference in "learning by doing" ability. Second, we show that the long-term sustained economic growth is achievable if robots are capable of machine learning abilities, which makes robots smarter than human labor. Third, we provide the factors which influence the long-term economic growth rate.

The structure of this paper is organized as follows. Section 2 summarizes the existing literature on robots and economic growth. In Section 3, we build up a theoretical model to investigate the economic growth considering 
robots with machine learning ability. After considering the machine learning ability of robots, the endogenous growth model based on the concepts of "learning by doing" is established for the long-term equilibrium analysis. To illustrate our theoretical results in a more intuitive way, a numerical study is provided in Section 4. We summarize and conclude in the last section of this paper.

\section{LITERATURE REVIEW}

In this section, we review the existing literature which relates to us the most. First, we review the work which projects the impacts of technical progress on economic growth. Second, we summarize the prior literature showing the impacts of robots regarding economic growth.

In terms of research on the economic influences of technological development, the development of information and communication technology has increased labor productivity, which is supported by some empirical studies [13-15]. There is also some literature about how to make full use of information technology to improve the efficiency of firms' operations $[16,17]$. However, Gordon [18] expressed a pessimistic view that the real GDP per capita in the United States would not maintain continuous growth, and the productivity growth brought by technological progress might have a gradual slowing trend.

As more and more robots are brought into production for the sake of productivity increments and cost savings, economists start to focus on the positive impacts of robots on economic growth in a natural way. As for theoretical models, Fernald and Jones [19] argue that education and R\&D investments are the two main drivers for the US economic growth during the past decades, but with the gradual weakening of these drivers, the economic growth is likely to slow down. However, the use of AI and robots raises fundamental uncertainties about future growth: AI will increase the chance that machines will replace workers to some extent, and thus may lead to higher growth in the future. Even, in some cases, if capital can completely replace Labor, growth rates could skyrocket. Prettner's [7] theoretical model extends the Solow model [20] and further explains this phenomenon. The production factors can be divided into three categories, human capital, traditional capital, and automatic capital (e.g., robots, 3D printers, and driverless cars, etc.). His production function is established on the assumption that labor and automated capital are completely substituted for the other. He shows that technological progress and the emergence of robots can indeed promote the development of the economy. If automated capital can completely replace the labor force, the economy can achieve permanent growth even without technological progress. In terms of empirical research, Kromann et al. [1] use panel data of robot inventories of 9 industries in 10 countries from the IFR database and EU KLEMS database, showing that the application of industrial robots has a significant positive effect on labor productivity. Acemoglu and Restrepo [21] studied the relationship between the aging problem, economic growth, and robot investment. The aging problems will hurt economic growth. One of the main reasons is the low labor force participation rate and lower productivity of older workers [22]. The second reason is that aging will lead to more savings than expected investment, leading to long- term stagnation [23, 24]. However, Acemoglu and Restrepo [21] proved that there was no such negative correlation in the empirical study. In the countries experiencing a faster-aging problem, automation is being adopted faster and industrial robots are more densely used. Graetz and Micheals [3] also employ datasets of IFR and EU KLEMS to conclude that the use of industrial robots improves labor productivity and total factor productivity.

The above theoretical research justifies that robots will have a positive impact on growth issues, and empirical research also confirms that the use of robots will promote labor productivity. But some studies suggest an opposite point of view. Gasteiger and Prettner [10] apply the Diamond model [25] as a benchmark, assuming that household savings come entirely from labor income. However, the competition between robots and the labor force reduces the wage rate, thus reducing labor force income, thereby reducing household savings and investment, and hindering economic growth. Sachs and Kotlikoff [8] believe that intelligent robots and young unskilled labor force are in a mutually substitutive relation, while old skilled labor forces are complements to robots. Falling wages of young labor forces reduce their ability to save and limit their investments in acquiring skills and capital. Benzell et al. [11] express the smart machine as a combination of capital and code and divided people in the labor market into high-tech and low-tech ones. Among them, high-tech labor force can produce codes. He demonstrates that the participation of robots will reduce the wages of labor in the long run. In such a case, higher gross demand in the future cannot be satisfied by a lower aggregated demand since the emergence of robots exploits a part of the income of consumers.

Although prior literature discusses the impacts of the robot on the labor market and economic development, most of them simply regard the robots as a substitute during the production process. Most of these studies have not considered the characteristics of robots in their model. In the future, if AI technology reaches and exceeds the normal level of human intelligence, a series of very different considerations will occur [26]. Based on the current development prospect of AI, some optimistic scientists believe that AI will surpass human intelligence in 2029 [27]. Some neutral scientists believe that there is a $90 \%$ probability that AI will reach the level of general human intelligence in this century [28]. In the coming decades, based on the development of information technology and machine learning technology, robots will master all human knowledge and skills, even including the ability to recognize patterns and solve problems, and its self-learning ability will probably surpass that of humans after the application of machine learning technology. Given these predictions, we have to think about and discuss the impact of general AI on humans. Therefore, based on such a prediction, this paper builds up an economic growth model that takes robot machine learning ability into account.

\section{THEORETICAL MODEL}

\subsection{Model Preliminaries}

Our theoretical model considers two main characteristics of robots in the production process. The first one is the replacement role of robots in the labor force. The 
second one is the machine learning ability of robots that is distinct from the human workforce. In this paper, we establish an economic growth model considering these two characteristics of robots. Before introducing the details of our model, we introduce the model of Prettener [7] as a benchmark.

At present, many studies on the basic idea of robots entering the production process are based on the idea that robots are substitutes for human labor forces [7, 29, 30]. For instance, Prettener [7], as an extension of Solow's growth model, assumes that the production factors in the production process are divided into three categories: labor force, robot, and capital. In his model, the production function takes the form of a Cobb-Douglas production function as follows:

$$
Y_{t}=A_{t}\left(L_{t}+R_{t}\right)^{\alpha} K_{t}^{1-\alpha},
$$

The notations applied in our model are shown in Table A in Appendix A. In addition, Prettener [7] assumes that the labor force grows at a rate of $n$, and the traditional capital and robots can be accumulated, assuming that the depreciation rate is the same, both are $\delta$. In this production function, labor and capital are incomplete substitutes, while labor and robot are complete substitutes.

In Prettener's model, technological progress $A_{t}$ is assumed to be completely exogenous. In that case, the impacts of technological progress and efficiency improvement caused by machine learning ability and experience accumulation of robots are not considered. In our model, the above model is extended with other assumptions unchanged. The output function in our model is shown in Eq. (2):

$$
Y_{t}=\left(A_{R t} R_{t}+A_{L t} L_{t}\right)^{\alpha} K_{t}^{1-\alpha},
$$

The notations applied in our model are shown in Table A in Appendix A. In this paper, we assume that the robot has the ability of machine learning. With the accumulation of knowledge and capital, the robot's work efficiency will increase significantly. Based on the idea of "Learning by doing" of endogenous growth theory [31, 32], $A_{R t}$ is expressed in the following form:

$$
A_{R t}=B K_{t}^{\theta}, B>0, \theta>0 .
$$

Besides, we assume that the speed of robots' machine learning is much faster than that of labor force. In that case, $A_{L t}$ is expressed as

$A_{L t}=C K_{t}^{\lambda}, C>0, \theta>\lambda>0$.

$\theta>\lambda$ indicates that the robot is better at learning than the labor force. Thus, the resulting output function in our model is

$$
Y_{t}=\left(B K_{t}^{\theta} R_{t}+C K_{t}^{\lambda} L_{t}\right)^{\alpha} K_{t}^{1-\alpha} .
$$

The notations applied in our model are shown in Table A in Appendix A.

\subsection{Comparative Statics Analysis and Long-term Equilibrium}

In perfect competition, we can obtain the return of the robot $w_{t}^{R}$, the wage of the labor force $w_{t}^{L}$, and the return of traditional capital $w_{t}^{K}$ as follows:

$$
\begin{aligned}
& w_{t}^{R}=\frac{\partial Y_{t}}{\partial R_{t}}=\alpha B K_{t}^{1-\alpha+\theta}\left(B K_{t}^{\theta} R_{t}+C K_{t}^{\lambda} L_{t}\right)^{\alpha-1} . \\
& w_{t}^{L}=\frac{\partial Y_{t}}{\partial L_{t}}=\alpha C K_{t}^{1-\alpha+\lambda}\left(B K_{t}^{\theta} R_{t}+C K_{t}^{\lambda} L_{t}\right)^{\alpha-1} . \\
& w_{t}^{K}=\frac{\partial Y_{t}}{\partial K_{t}}=1-\alpha K_{t}^{-\alpha}\left(B K_{t}^{\theta} R_{t}+C K_{t}^{\lambda} L_{t}\right)^{\alpha}+ \\
& +\alpha B \theta R_{t} K_{t}^{\theta-1}+C \lambda L_{t} K_{t}^{\lambda-1}\left(B K_{t}^{\theta} R_{t}+C K_{t}^{\lambda} L_{t}\right)^{\alpha-1} K_{t}^{1-\alpha} .
\end{aligned}
$$

Based on the above analysis, we have Proposition 1 and Proposition 2 as follows.

Proposition 1. With other parameters unchanged, the output is increasingly concave in the inputs of robots.

Proof of Proposition 1 is shown in Appendix B.

It is intuitive that as the input of robots increases, total output will increase. However, the robot's marginal output is diminishing. Therefore, there exists an optimal robot investment level in the production process. More robots are not always better. We can find the detailed analysis in Section 4.

Proposition 2. The return gap between robots and labor depends on the learning ability of robots and labor. More specifically, (1) when the learning ability of the robot is stronger than that of labor, the return gap between robot and labor increases as the capital inputs increase. (2) When the learning ability of the labor force is stronger than that of the robot, the return gap between the robot and the labor force decreases as the capital inputs increase.

Proof of Proposition 2 is shown in Appendix B.

We believe that in the future, based on the development of information technology and machine learning technology, robots will master all human knowledge and skills, even including the ability to recognize patterns and solve problems, and its self-learning ability will probably surpass that of humans after the application of machine learning technology. Therefore, in our paper we will focus on the case when $\theta-\lambda>0$ holds.

Next, we derive the long-term equilibrium of our model. The change rate of traditional capital $\dot{K}_{t}$ and robot $\dot{R}_{t}$ is shown as follows:

$$
\begin{aligned}
& \dot{K}_{t}=s\left(1-s_{r}\right)\left(B K_{t}^{\theta} R_{t}+C K_{t}^{\lambda} L_{t}\right)^{\alpha} K_{t}^{1-\alpha}-\delta K_{t} . \\
& \dot{R}_{t}=s s_{r}\left(B K_{t}^{\theta} R_{t}+C K_{t}^{\lambda} L_{t}\right)^{\alpha} K_{t}^{1-\alpha}-\delta R_{t} .
\end{aligned}
$$

Therefore, the growth rate of capital $g_{K}$ and robot $g_{R}$ can be written as

$$
\begin{gathered}
g_{K} \equiv \frac{\dot{K}_{t}}{K_{t}}=s\left(1-s_{r}\right)\left(\frac{B K_{t}^{\theta} R_{t}+C K_{t}^{\lambda} L_{t}}{K_{t}}\right)^{\alpha}-\delta . \\
g_{R} \equiv \frac{\dot{R}_{t}}{R_{t}}=s s_{r} \frac{\left(B K_{t}^{\theta} R_{t}+C K_{t}^{\lambda} L_{t}\right)^{\alpha} K_{t}^{1-\alpha}}{R_{t}}-\delta .
\end{gathered}
$$


By simplifying the overall growth rate into the form of per capita, we obtain the growth rate of capital $g_{k}$ and robots $g_{k}$ in terms of per capita as

$g_{k} \equiv \frac{\dot{k_{t}}}{k_{t}}=s\left(1-s_{r}\right)\left(\frac{L_{t}^{\theta} r_{t} B k_{t}^{\theta}+C L_{t}^{\lambda} k_{t}^{\lambda}}{k_{t}}\right)^{\alpha}-\delta-n$.

$g_{k} \equiv \frac{\dot{r}_{t}}{r_{t}}=s s_{r}\left(\frac{L_{t}^{\theta} r_{t} B k_{t}^{\theta}+C L_{t}^{\lambda} k_{t}^{\lambda}}{r_{t}}\right)^{\alpha}\left(\frac{k_{t}}{r_{t}}\right)^{1-\alpha}-\delta-n$.

Where lowercase letters refer to variables in terms of the per worker units. In the Appendix $\mathrm{C}$ we show that the following dynamic system fully characterizes the evolution of the economy.

$$
\begin{aligned}
& g_{g_{k}+\delta+n}=\alpha \theta n+\alpha(\theta-1) g_{k}+\alpha g_{r} . \\
& g_{g_{r}+\delta+n}=\alpha \theta n+(\alpha \theta-\alpha+1) g_{k}-(1-\alpha) g_{r},
\end{aligned}
$$

where $g_{g_{k}+\delta+n}$ is the growth rate of $\left(g_{k}+\delta+n\right)$ and $g_{g_{r}+\delta+n}$ is the growth rate of $\left(g_{r}+\delta+n\right)$.

Next, we investigate the evolutions of $k_{t}$ and $r_{t}$ by illustrating the long-term equilibrium with phase diagrams. We first examine the dynamics of $k_{t}$. We then investigate the evolution of $r_{t}$.

(1) The dynamics of $k_{t}$.

Since $g_{g_{k}+\delta+n}=\alpha\left[\theta n+g_{r}-(1-\theta) g_{k}\right]$, we divide the discussion into three parts depending on the relation between $g_{k}$ and $\frac{\theta n}{1-\theta}+\frac{1}{1-\theta} g_{r}$.

(I) When $g_{k}=\frac{\theta n}{1-\theta}+\frac{1}{1-\theta} g_{r}, \quad g_{g_{k}+\delta+n}=0$, then $g_{g_{k}}=0$

(II) When $g_{k}<\frac{\theta n}{1-\theta}+\frac{1}{1-\theta} g_{r}, \quad g_{g_{k}}>0, \quad g_{k}$ increases;

(III) When $g_{k}>\frac{\theta n}{1-\theta}+\frac{1}{1-\theta} g_{r}, \quad g_{g_{k}}<0, \quad g_{k}$ decreases.

As shown in Fig. 1, when $\theta>\lambda>0$, the slope of the solid line is greater than 1 . Thus, the corresponding phase diagram is as follows:

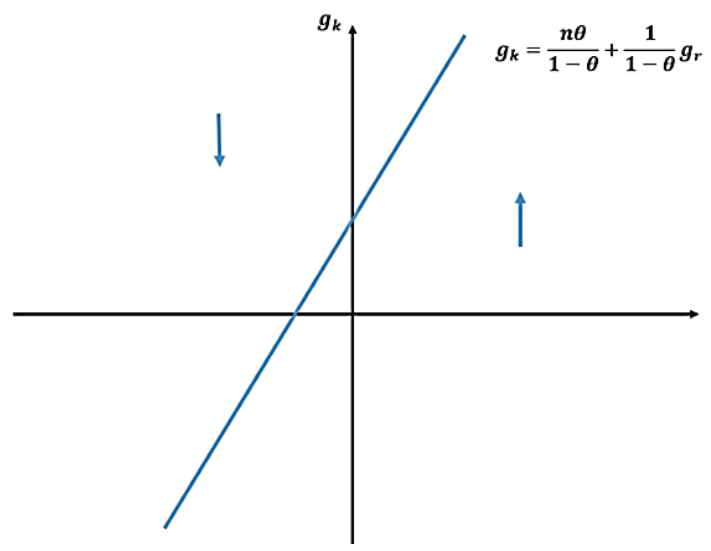

Figure 1 Change in the growth rate of capital per capita
(2) The dynamics of $r_{t}$.

Since $g_{g_{r}+\delta+n}=\alpha \theta n+(\alpha \theta-\alpha+1) g_{k}-(1-\alpha) g_{r}$, we divide the discussion into three parts depending on the relation between $g_{k}$ and $-\frac{n \alpha \theta}{\alpha \theta-\alpha+1}+\frac{1-\alpha}{\alpha \theta-\alpha+1} g_{r}$.

(I) When $g_{k}=-\frac{n \alpha \theta}{\alpha \theta-\alpha+1}+\frac{1-\alpha}{\alpha \theta-\alpha+1} g_{r}$, $g_{g_{r}+\delta+n}=0$, then $g_{g_{r}}=0$;

(II)

$$
\text { When } \quad g_{k}>-\frac{n \alpha \theta}{\alpha \theta-\alpha+1}+\frac{1-\alpha}{\alpha \theta-\alpha+1} g_{r},
$$

$g_{g_{r}}>0, g_{r}$ increases;

(III) When $g_{k}<-\frac{n \alpha \theta}{\alpha \theta-\alpha+1}+\frac{1-\alpha}{\alpha \theta-\alpha+1} g_{r}$, $g_{g_{r}}<0, g_{r}$ increases.

The phase diagram is shown in Fig. 2 as follows:

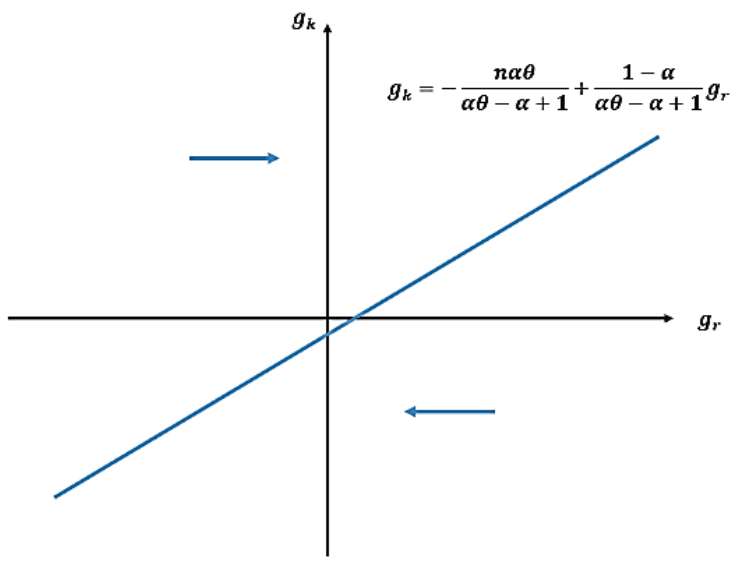

Figure 2 Change in the growth rate of robots per capita

When $\theta>\lambda>0$, we obtain Fig. 3 below by combining Fig. 1 and Fig. 2.

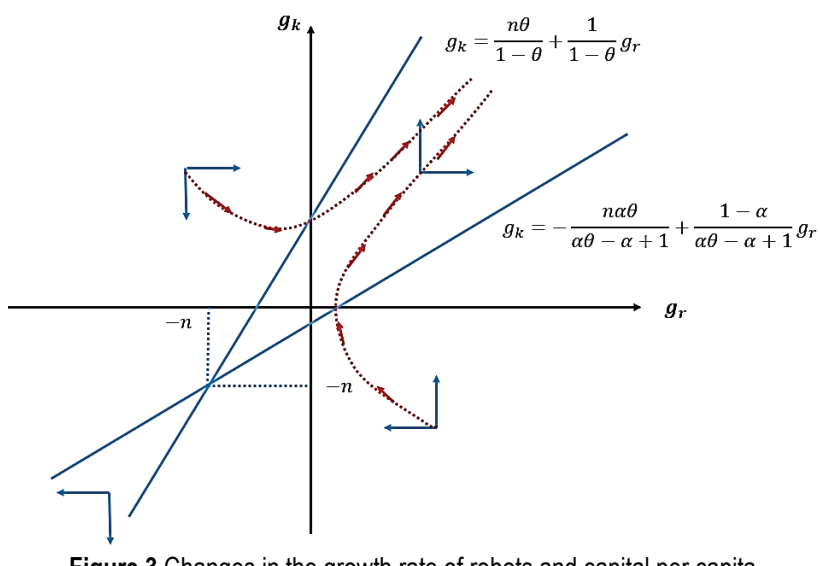

Figure 3 Changes in the growth rate of robots and capital per capita

From the above analysis and Fig. 3, we have Proposition 3.

Proposition 3. When the learning ability of robots is stronger than human capital, there will be no balanced growth path for the economy, and the economy will eventually show a sustained growth pattern, and the growth rate of capital per capita, output per capita and robot per capita will keep growing. 
When we consider the strong machine learning ability of robots, the growth rate of traditional capital and robot per capita is greater than zero, that is to say, the growth rate of capital, output, and robot per capita keeps increasing.

\section{NUMERICAL STUDY}

To illustrate the theoretical analysis more intuitively, we employ a numerical study in this section. We first conduct a comparative analysis of the machine learning capability of robots. Then we illustrate the long-term economic growth rate with different learning abilities of robots and different percentages of total savings invested in robots. We start from the comparative analysis. Tab. 1 shows the parameter values of the comparative analysis.

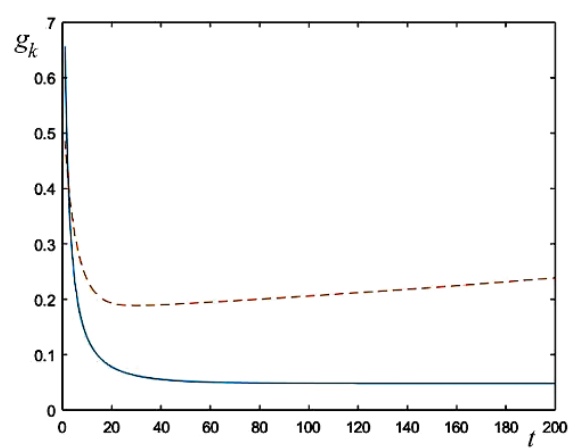

a)

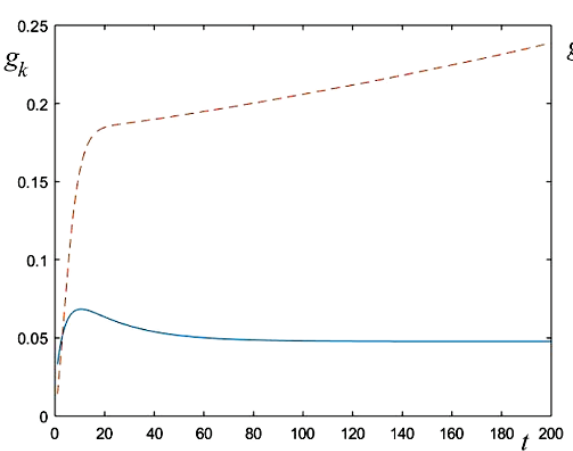

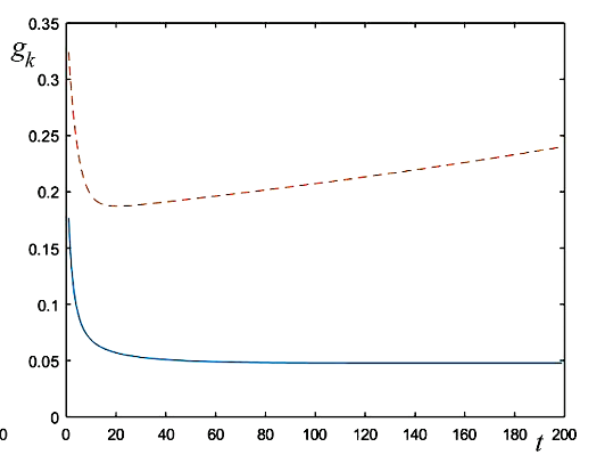

c)

Figure 4 a) The growth rate of capital per capita; b) The growth rate of robot per capita; c) The growth rate of output per capita

In Fig. 4(a-c), the dotted line shows the numerical results when the robot's learning ability is stronger than that of the human labor force. The solid line shows the results when the robot has no machine learning ability. By comparing these figures, we can conclude that when the robots have no machine learning ability, the growth rate of output per person tends to be constant. The growth rate of output per person will continue to increase when robots have machine learning capabilities that are stronger than the average human labor force.

Then we illustrate the relationship between robot learning ability and per capita output growth rate in Fig. 5 and the relationship between percentage of total savings invested in robots and per capita output growth rate in Fig. 6. The parameter values are shown in Tab. 2 .

Table 2 Parameter values of machine learning growth model

Table 2 Parameter values of machine learning growth model
\begin{tabular}{|c|c|c|c|c|c|c|c|c|c|c|}
\hline & $n$ & $s$ & $\alpha$ & $\delta$ & $s_{r}$ & $\theta$ & $\lambda$ & $B$ & $C$ & $t$ \\
\hline Fig. 5 & 0.005 & 0.48 & 0.7 & 0.04 & 0.1 & $/$ & 0 & 1 & 1 & 200 \\
\hline Fig. 6 & 0.005 & 0.48 & 0.7 & 0.04 & $/$ & 0.01 & 0 & 1 & 1 & 200 \\
\hline
\end{tabular}

Fig. 5 shows the relationship between robot machine learning ability and per capita output growth rate:

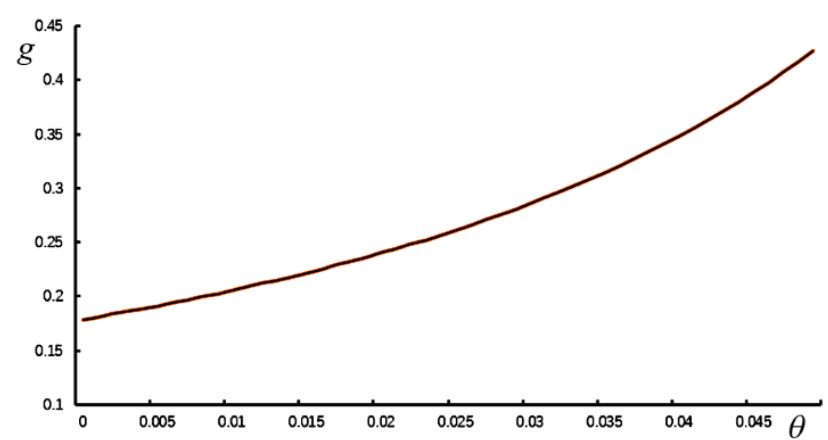

Figure 5 The relationship between robot learning ability and per capita output growth rate
From Fig. 5, we have the following proposition.

Proposition 4. The robot learning ability and per capita output growth rate are positively related.

With the rapid development of AI technology, we believe that the learning ability of robots will increase in the long run. Besides, the research and development investment for improving robot learning ability is of great importance.

Fig. 6 shows the relationship between percentage of total savings invested in robots and per capita output growth rate:

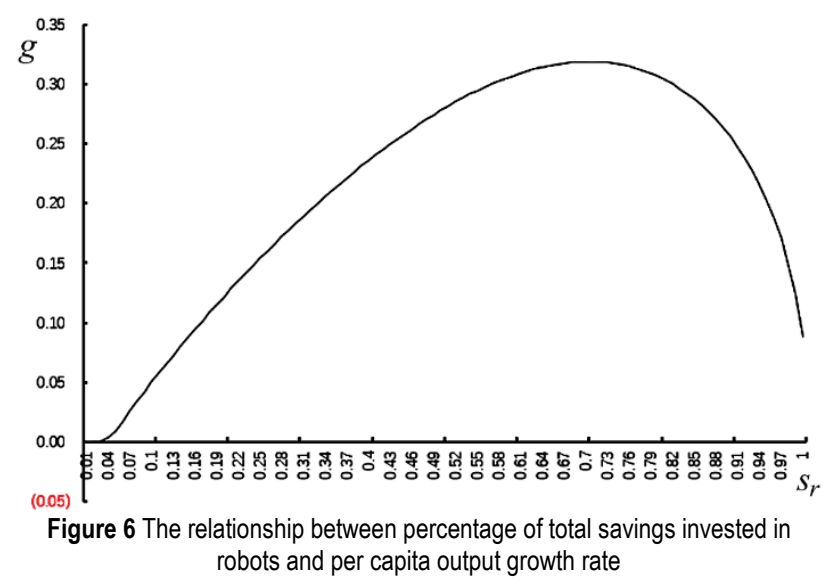

From Fig. 6, we have Proposition 5 as follows.

Proposition 5. There is an optimal robot investment ratio to maximize the long-term growth rate of output per capita.

More robots are not always better. Combined with the findings in Proposition 5, we should not only focus on increasing the amount of robot investment, and we should also focus on the quality and learning ability of robots. 


\section{CONCLUSION}

We consider robot as a unique factor of production, not only considering its substitution effect on labor force, but also considering its essential difference from labor force and traditional capital in the production process. We believe that the difference mainly comes from the application of AI technology to the robot, so that it has the ability of machine learning, and this ability may surpass human labor force in the near future. Thus, the robot can accumulate experience and work efficiency in the work. We take the aforementioned essential difference of robots into our theoretical model. Based on the endogenous growth model with the idea of "learning by doing", this paper analyzes the impact of the use of robots on long-term economic growth. Our results show that (1) With other parameters unchanged, the output is increasingly concave in the inputs of robots; (2) The return gap between robots and labor depends on the learning ability of robots and labor; (3) When the learning ability of robots is stronger than human capital, there will be no balanced growth path for the economy, and the economy will eventually show a sustained growth pattern, and the growth rate of capital per capita, output per capita and robot per capita will keep growing; (4) The robot learning ability and per capita output growth rate are positively related; (5)There is an optimal robot investment ratio to maximize the long-term growth rate of output per capita.

AI technology and the rapid development of robot technology have brought new power in various fields. As for the developed countries, the application of robots provides favorable conditions for them to carry out "reindustrialization", reshape the national manufacturing competitiveness and develop emerging industries. It also brings new opportunities and challenges for emerging developing countries to maintain their competitive advantages in manufacturing, upgrade their industrial structure and optimize their employment structure. In our paper, we conclude that the application of the robot may boost the economy to some extent. However, more robots are not always better. Combined with Proposition 5, managers should not only increase investments in robots. How to improve the learning ability of robots is also of great importance.

\section{Acknowledgements}

This work was supported by the Fundamental Funds for the Ministry of Education in China (MOE) Project of Humanities and Social Sciences (No. 19YJC630137), the National Natural Science Foundation (No. J1824031, No. 71390334, and No. 71802037), the Fundamental Research Funds for the Central Universities in UIBE (No. CXTD1005), and the Fundamental Research Funds for the Central Universities (No. 2020JJ006, No. 3132019223). This support is gratefully acknowledged.

\section{REFERENCES}

[1] Kromann, L., Skaksen, J. R., \& Sørensen, A. (2011). Automation, labor productivity and employment-a cross country comparison. CEBR, Copenhagen Business School.

[2] Muthukumaran, S. \& Sivaramakrishnan, R. (2019). Optimal Path Planning for an Autonomous Mobile Robot Using
Dragonfly Algorithm. International Journal of Simulation Modelling, 18(3), 397-407. http://dx.doi.org/10.2507/IJSIMM18(3)474

[3] Graetz, G. \& Michaels, G. (2018). Robots at work. Review of Economics and Statistics, 100(5), 753-768. https://doi.org/10.1162/rest_a_00754

[4] Gotlih, J., Brezocnik, M., Balic, J., Karner, T., Razborsek, B., \& Gotlih, K. (2017). Determination of accuracy contour and optimization of workpiece positioning for robot milling. Advances in Production Engineering \& Management, 12(3), 233-244. https://doi.org/10.14743/apem2017.3.254

[5] Huang, X. Q., Tang, X. T., \& Chen L. (2018). Simulation for Trajectory Tracking of Multi-Flexible-Link Space Robot with Deadzone. International Journal of Simulation Modelling, 17(4), 677-689. http://dx.doi.org/10.2507/IJSIMM17(4)459

[6] Supsomboon, S. \& Varodhomwathana, T. (2017). Robot and Plant Simulation for Automotive Part Production Process Design: A Case Study. International Journal of Simulation Modelling, 16(4), 617-629. http://dx.doi.org/10.2507/IJSIMM16(4)5.397

[7] Prettner, K. (2016). The implications of automation for economic growth and the labor share of income (No. 04/2016). ECON WPS-Vienna University of Technology, Working Papers in Economic Theory and Policy.

[8] Sachs, J. D. \& Kotlikoff, L. J. (2012). Smart machines and long-term misery (No. w18629). National Bureau of Economic Research. https://doi.org/10.3386/w18629

[9] Sachs, J. D., Benzell, S. G., \& LaGarda, G. (2015). Robots: Curse or blessing? A basic framework (No. w21091). National Bureau of Economic Research. https://doi.org/10.3386/w21091

[10] Gasteiger, E. \& Prettner, K. (2017). On the possibility of automation-induced stagnation (No. 07-2017). Hohenheim Discussion Papers in Business, Economics and Social Sciences.

[11] Benzell, S. G., Kotlikoff, L. J., LaGarda, G., \& Sachs, J. D. (2015). Robots are us: Some economics of human replacement (No. w20941). National Bureau of Economic Research. https://doi.org/10.3386/w20941

[12] Hémous, D. \& Olsen, M. (2014). The rise of the machines: Automation, horizontal innovation and income inequality. National Bureau of Economic Research. https://doi.org/10.2139/ssrn.2328774

[13] O'Mahony, M. \& Timmer, M. P. (2009). Output, input and productivity measures at the industry level: the EU KLEMS database. The Economic Journal, 119(538), F374-F403. https://doi.org/10.1111/j.1468-0297.2009.02280.x

[14] Stiroh, K. J. (2002). Information technology and the US productivity revival: what do the industry data say? American Economic Review, 92(5), 1559-1576. https://doi.org/10.1257/000282802762024638

[15] Bloom, N., Sadun, R., \& Van Reenen, J. (2012). Americans do IT better: US multinationals and the productivity miracle. American Economic Review, 102(1), 167-201. https://doi.org/10.1257/aer.102.1.167

[16] Gong, D., Liu, S., Tang, M., Ren, L., Liu, J., \& Liu, X. (2018). Revenue sharing or profit sharing? An internet production perspective. Advances in Production Engineering \& Management, 13(1), 81-92. https://doi.org/10.14743/apem2018.1.275

[17] Gong, D., Liu, S., Liu, J., \& Ren, L. (2019). Who benefits from online financing? A sharing economy E-tailing platform perspective. International Journal of Production Economics. https://doi.org/10.1016/j.ijpe.2019.09.011

[18] Gordon, R. J. (2012). Is US economic growth over? Faltering innovation confronts the six headwinds (No. w18315). National Bureau of Economic Research. https://doi.org/10.3386/w18315 
[19] Fernald, J. G. \& Jones, C. I. (2014). The future of US economic growth. American Economic Review, 104(5), 4449. https://doi.org/10.1257/aer.104.5.44

[20] Solow, R. M. (1957). Technical change and the aggregate production function. The Review of Economics and Statistics, 312-320. https://doi.org/10.2307/1926047

[21] Acemoglu, D. \& Restrepo, P. (2017). Robots and jobs: Evidence from US labor markets. NBER working paper, (w23285). https://doi.org/10.3386/w23285

[22] Summers, L. (2013). Why stagnation might prove to be the new normal. Financial Times, 15, 12.

[23] Murphy, K. M. \& Welch, F. (1990). Empirical age-earnings profiles. Journal of Labor Economics, 8(2), 202-229. https://doi.org/10.1086/298220

[24] Gordon, R. J. (2017). The rise and fall of American growth: The US standard of living since the civil war, Vol. 70, Princeton University Press. https://doi.org/10.1515/9781400888955

[25] Diamond, P. A. (1965). National debt in a neoclassical growth model. The American Economic Review, 55(5), 1126-1150.

[26] Korinek, A. \& Stiglitz, J. E. (2017). Artificial intelligence and its implications for income distribution and unemployment (No. w24174). National Bureau of Economic Research. https://doi.org/10.3386/w24174

[27] Kurzweil, R. (2005). The singularity is near: When humans transcend biology. Penguin.

[28] Bostrom, N. (2014). Superintelligence: Paths, Dangers, Strategies. Oxford: Oxford University Press.

[29] Autor, D. H., Levy, F., \& Murnane, R. J. (2003). The skill content of recent technological change: An empirical exploration. The Quarterly Journal of Economics, 118(4), 1279-1333. https://doi.org/10.1162/003355303322552801

[30] Acemoglu, D. \& Restrepo, P. (2018). The race between man and machine: Implications of technology for growth, factor shares, and employment. American Economic Review, 108(6), 1488-1542. https://doi.org/10.1257/aer.20160696

[31] Arrow, K. J. (1971). The economic implications of learning by doing. Review of Economic Studies, 29(3), 155-173. https://doi.org/10.2307/2295952

[32] Romer, P. M. (1986). Increasing returns and long-run growth. Journal of Political Economy, 94(5), 1002-1037. https://doi.org/10.1086/261420

[33] https://www.cnbc.com/2017/10/27/walmart-is-using-shelfscanning-robots-to-audit-its-stores.html

\section{Contact information:}

Jun LIU, Assistant professor

International Business School,

Beijing Foreign Studies University

No. 2, North Xisanhuan Road, Haidian District, Beijing, China

E-mail: liuj@bfsu.edu.cn

\section{Long REN, Assistant professor}

School of Information Technology and Management,

University of International Business and Economics

No. 10, Huixin East Road, Chaoyang District, Beijing, China

E-mail: renl@uibe.edu.cn

Xiang CHU, Associate professor

(Corresponding author)

School of Maritime Economics and Management,

Dalian Maritime University,

No. 1, Linghai Road, Dalian, Liaoning, China

E-mail: chuxiang@dlmu.edu.cn

Daqing GONG, Assistant professor

School of Economics and Management,

Beijing Jiaotong University,

No.3, Shangyuancun, Haidian District, Beijing, China

E-mail: gongdq@bjtu.edu.cn
Appendix A:

Table A The notations

\begin{tabular}{|c|c|}
\hline $\begin{array}{l}\frac{n}{8} \\
\text { है } \\
\text { है }\end{array}$ & Meanings \\
\hline$L_{t}$ & The amount of labor at time $t$ \\
\hline$R_{t}$ & The amount of robots at time $t$ \\
\hline$K_{t}$ & The amount of traditional capital at time $t$ \\
\hline$Y_{t}$ & The amount of total output at time $t$ \\
\hline$\alpha$ & $\begin{array}{l}\text { The share of output in the robot and labor sectors, } \\
0<\alpha<1\end{array}$ \\
\hline$\overline{A_{R t}}$ & Working efficiency of robots \\
\hline$A_{L t}$ & Working efficiency of labor \\
\hline$B$ & $\begin{array}{l}\text { Parameter that describes the learning ability (efficiency) } \\
\text { of robots }\end{array}$ \\
\hline$C$ & $\begin{array}{l}\text { Parameter that describes the learning ability (efficiency) } \\
\text { of labor }\end{array}$ \\
\hline$\theta$ & $\begin{array}{l}\text { Parameter that describes the learning ability (efficiency) } \\
\text { of robots }\end{array}$ \\
\hline$\lambda$ & $\begin{array}{l}\text { Parameter that describes the learning ability (efficiency) } \\
\text { of labor }\end{array}$ \\
\hline$s$ & Saving rate \\
\hline$s_{r}$ & The percentage of total savings invested in robots \\
\hline$n$ & The growth rate of the labor force \\
\hline$\delta$ & The rate of depreciation of robots and traditional capital \\
\hline
\end{tabular}

\section{Appendix B:}

Proof of Proposition 1.

$\frac{\partial Y_{t}}{\partial R_{t}}=\alpha B K_{t}^{\theta+1-\alpha}\left(B K_{t}^{\theta} R_{t}+C K_{t}^{\lambda} L_{t}\right)^{\alpha-1}>0$
$\frac{\partial^{2} Y_{t}}{\partial R_{t}^{2}}=\alpha(\alpha-1) B^{2} K_{t}^{2 \theta+1-\alpha}\left(B K_{t}^{\theta} R_{t}+C K_{t}^{\lambda} L_{t}\right)^{\alpha-2}<0$

since $0<\alpha<1$. Proven.

Proof of Proposition 2.

$\frac{w_{R}}{w_{L}}=\frac{B}{C} K_{t}^{\theta-\lambda}$

When robots are better at learning than the workforces, i.e., $\theta-\lambda>0, w_{R} / w_{L} \geq 0$. When the workforce is better at learning than the robot, i.e., $\theta-\lambda<0, w_{R} / w_{L}<0$. Proven.

\section{Appendix C:}

Derivations of the long-run accumulation rate of robots, using Eq. (16) and (17), we have:

$$
\begin{aligned}
& g_{k}+\delta+n=s\left(1-s_{r}\right)\left(\frac{L_{t}^{\theta} r_{t} B k_{t}^{\theta}+C L_{t}^{\lambda} k_{t}^{\lambda}}{k_{t}}\right)^{\alpha}, \\
& g_{r}+\delta+n=s s_{r}\left(\frac{L_{t}^{\theta} r_{t} B k_{t}^{\theta}+C L_{t}^{\lambda} k_{t}^{\lambda}}{r_{t}}\right)^{\alpha}\left(\frac{k_{t}}{r_{t}}\right)^{1-\alpha} .
\end{aligned}
$$


$\ln \left(g_{k}+\delta+n\right)=\ln (s)+\ln \left(1-s_{r}\right)+$

$+(\alpha) \ln \left(B L_{t}^{\theta} r_{t} k_{t}^{\theta}+C L_{t}^{\lambda} k_{t}^{\lambda}\right)-\alpha \ln \left(k_{t}\right)$,

$\ln \left(g_{r}+\delta+n\right)=$

$=\ln (s)+\ln s_{r}+(\alpha) \ln \left(B L_{t}^{\theta} r_{t} k_{t}^{\theta}+C L_{t}^{\lambda} k_{t}^{\lambda}\right)-$

$-\alpha \ln \left(r_{t}\right)+(1-\alpha) \ln \left(k_{t}\right)-(1-\alpha) \ln \left(r_{t}\right)$.

Then we have:

$\ln \left(g_{k}+\delta+n\right)=$

$=\ln (s)+\ln \left(1-s_{r}\right)+(\alpha) \ln \left(L_{t}^{\lambda} k_{t}^{\lambda}\right)+$

$+(\alpha) \ln \left(B L_{t}^{\theta-\lambda} r_{t} k_{t}^{\theta-\lambda}+C\right)-\alpha \ln \left(k_{t}\right)$,

$\ln \left(g_{r}+\delta+n\right)=\ln (s)+\ln s_{r}+(\alpha) \ln \left(L_{t}^{\lambda} k_{t}^{\lambda}\right)+$

$+(\alpha) \ln \left(B L_{t}^{\theta-\lambda} r_{t} k_{t}^{\theta-\lambda}+C\right)-\alpha \ln \left(r_{t}\right)+$

(C-

$+(1-\alpha) \ln \left(k_{t}\right)-(1-\alpha) \ln \left(r_{t}\right)$.

6)

The growth rate of $\left(g_{k}+\delta+n\right)$ :

$g_{g_{k}+\delta+n}=\alpha \lambda n+\alpha \lambda \frac{\dot{k}_{t}}{k_{t}}+\alpha \frac{B L_{t}^{(\theta-\lambda)} \dot{r}_{t} k_{t}^{(\theta-\lambda)}}{B L_{t}^{(\theta-\lambda)} r_{t} k_{t}^{(\theta-\lambda)}+C}+$

$+\alpha \frac{B(\theta-\lambda) L_{t}^{(\theta-\lambda)} k_{t}^{(\theta-\lambda)-1} \dot{k}_{t} r_{t}}{B L_{t}^{(\theta-\lambda)} r_{t} k_{t}^{(\theta-\lambda)}+C}+$

$+\alpha \frac{B(\theta-\lambda) L_{t}^{(\theta-\lambda)-1} k_{t}^{(\theta-\lambda)} \dot{L}_{t} r_{t}}{B L_{t}^{(\theta-\lambda)} r_{t} k_{t}^{(\theta-\lambda)}+C}-\alpha \frac{\dot{k}_{t}}{k_{t}}$.

Because $\theta>\lambda$, at the long-run equilibrium, $B L_{t}^{(\theta-\lambda)} r_{t} k_{t}^{(\theta-\lambda)} \gg C$.

$\frac{B L_{t}^{(\theta-\lambda)} \dot{r}_{t} k_{t}^{(\theta-\lambda)}}{B L_{t}^{(\theta-\lambda)} r_{t} k_{t}^{(\theta-\lambda)}+C} \approx \frac{B L_{t}^{(\theta-\lambda)} \dot{r}_{t} k_{t}^{(\theta-\lambda)}}{B L_{t}^{(\theta-\lambda)} r_{t} k_{t}^{(\theta-\lambda)}}$

$\frac{B(\theta-\lambda) L_{t}^{(\theta-\lambda)} k_{t}^{(\theta-\lambda)-1} \dot{k}_{t} r_{t}}{B L_{t}^{(\theta-\lambda)} r_{t} k_{t}^{(\theta-\lambda)}+C} \approx \frac{B(\theta-\lambda) L_{t}^{(\theta-\lambda)} k_{t}^{(\theta-\lambda)-1} \dot{k}_{t} r_{t}}{B L_{t}^{(\theta-\lambda)} r_{t} k_{t}^{(\theta-\lambda)}}$

$\frac{B(\theta-\lambda) L_{t}^{(\theta-\lambda)-1} k_{t}^{(\theta-\lambda)} \dot{L}_{t} r_{t}}{B L_{t}^{(\theta-\lambda)} r_{t} k_{t}^{(\theta-\lambda)}+C} \approx \frac{B(\theta-\lambda) L_{t}^{(\theta-\lambda)-1} k_{t}^{(\theta-\lambda)} \dot{L}_{t} r_{t}}{B L_{t}^{(\theta-\lambda)} r_{t} k_{t}^{(\theta-\lambda)}}$

We have

$g_{g_{k}+\delta+n}=\alpha \theta n+\alpha \lambda \frac{\dot{k_{t}}}{k_{t}}+\alpha \frac{\dot{k_{t}}}{k_{t}}+\alpha(\theta-\lambda) \frac{\dot{k_{t}}}{k_{t}}+$

$+\alpha(\theta-\lambda) n-\alpha \frac{\dot{k_{t}}}{k_{t}}=\alpha \theta n+\alpha(\theta-1) g_{k}+\alpha g_{r}$

The growth rate of $\left(g_{r}+\delta+n\right)$ :

$$
\begin{aligned}
& g_{g_{r}+\delta+n}=\alpha \lambda n+\alpha \lambda \frac{\dot{k}_{t}}{k_{t}}+\alpha \frac{B L_{t}^{(\theta-\lambda)} \dot{r}_{t} k_{t}^{(\theta-\lambda)}}{B L_{t}^{(\theta-\lambda)} r_{t} k_{t}^{(\theta-\lambda)}+C}+ \\
& +\alpha \frac{B(\theta-\lambda) L_{t}^{(\theta-\lambda)} k_{t}^{(\theta-\lambda)-1} \dot{k}_{t} r_{t}}{B L_{t}^{(\theta-\lambda)} r_{t} k_{t}^{(\theta-\lambda)}+C}+ \\
& +\alpha \frac{B(\theta-\lambda) L_{t}^{(\theta-\lambda)-1} k_{t}^{(\theta-\lambda)} \dot{L}_{t} r_{t}}{B L_{t}^{(\theta-\lambda)} r_{t} k_{t}^{(\theta-\lambda)}+C}- \\
& -\alpha \frac{\dot{r}_{t}}{r_{t}}+(1-\alpha) \frac{\dot{k}_{t}}{k_{t}}-(1-\alpha) \frac{\dot{r}_{t}}{r_{t}}
\end{aligned}
$$

Because $\theta>\lambda$, at the long-run equilibrium, $B L_{t}^{(\theta-\lambda)} r_{t} k_{t}^{(\theta-\lambda)} \gg C$, we have

$g_{g_{r}+\delta+n}=\alpha \lambda n+\alpha \lambda \frac{\dot{k}_{t}}{k_{t}}+\alpha \frac{\dot{r}_{t}}{r_{t}}+\alpha(\theta-\lambda) \frac{\dot{k_{t}}}{k_{t}}+$

$+\alpha(\theta-\lambda) n-\alpha \frac{r_{t}}{r_{t}}+(1-\alpha) \frac{\dot{k}_{t}}{k_{t}}-(1-\alpha) \frac{\dot{r}_{t}}{r_{t}}=$

$=\alpha \theta n+(\alpha \theta-\alpha+1) g_{k}-(1-\alpha) g_{r}$ 